\title{
Being a Correct Presumption vs. Being Presumably the Case
}

\section{LILIAN BERMEJO-LUQUE}

\author{
Department of Philosophy I \\ University of Granada \\ Edificio de Psicología. Campus de Cartuja, s/n. \\ Granada 18071, Spain \\ lilianbl@ugr.es
}

\begin{abstract}
Presuming that $p$ is not the same as maintaining that presumably $p$. I argue that, in presuming that $p$, we make a presumption, whereas in maintaining that presumably $p$, we draw the conclusion of a presumptive inference. I provide an account of the correctness conditions for presumptions and presumptive inferences by characterizing presumptions as a type of constative speech-act having certain semantic correctness conditions and by dealing with the correctness conditions for the use of an epistemic modal such as "presumably." Such an epistemic modal is characterized as the force indicator for a speech-act of concluding involving a presumptive inference.
\end{abstract}

Résumé: Présumer que $p$ est différent de maintenir que $p$ est présumable. Je soutiens qu'en présumant que $p$, nous faisons une présomption, alors qu'en soutenant que $p$ est présumable, nous tirons la conclusion d'une inférence présomptive. Je donne un compte des conditions d'exactitude pour les présomptions et les inférences présomptives en caractérisant des présomptions comme un type d'acte de discours constatif ayant certaines conditions de régularité sémantique, d'une part, et en traitant les conditions d'exactitude pour l'utilisation d'expression modale modal épistémique telle que " $p$ est présumable ", d'autre part. Une telle expression est caractérisée comme la force d'un acte de parole qui indique une conclusion impliquant une inférence présomptive.

Keywords: burden of proof, LNMA, presumptions, presumptive inferences, presumptions of fact, presumptions of law,

\section{Introduction}

The nature of presumptions is a topic of special interest within the field of law; not only because legal systems are abound with so called presumptions of law, but also because some of these presumptions, such as the presumption of innocence and the different presumptions of validity (of patents, of land-use, of court decisions, etc) are supposed to determine the very legitimacy of judicial procedures.

Philosophers have also paid attention to presumptions as devices for reaching conclusions under uncertainty. In this nontechnical sense, presumptions exceed the realm of law, playing a 
widespread cognitive role in both everyday and scientific reasoning. Contemporary philosophers and argumentation theorists working on presumptions like Nicholas Rescher (1977; 2006), Douglas Walton $(1992 ; 1993 ; 1996 ; 2008)$ and James Freeman (2005) even contend that presumptions are unavoidable points of departure for any inquiry, and thus, conditions of possibility for achieving justification for our claims and beliefs. For, on the one hand, presumptions would articulate the exemption of providing further reasons for our reasons, which is something necessary if chains of reasoning are to stop at some point. And regarding argumentative exchanges, presumptions would serve to allocate the burden of proof among discussants, determining the path for a correct argumentative discussion to take place.

But what is a presumption? Philosophical literature shows a contrast between inferential and dialogical approaches. Classical authors such as Richard Whately (1884), Alfred Sidgwick (1886) and, more recently, Edna Ullman-Margalit (1983) took presumptions to be the conclusions of inferences made on the basis of a presumptive rule and a presumption-raising fact. For their part, Walton, Freeman and Rescher have characterized the presumptive status of a claim as a dialogical status instead. In their view, such presumptive status may be warranted either inferentially or from a source, and it amounts to making the claim stand until new evidence tells otherwise. As a result, presumptions are conceived as tentative claims to truth subject to rules of introduction and elimination that are, in the last resort, a matter of the pragmatics of dialogical procedures.

This paper focuses on the role of presumptions within argumentation by considering the difference between presumptions and presumptive inferences. Contrary to the inferentialist approach, it is argued that making presumptions does not involve making inferences - whether presumptive or not. Instead, presumptions are characterized as non-inferential speech-acts, which was also Walton's original strategy. Yet, contrary to Walton and those defending a dialogical approach, I argue that presumptions do not necessarily involve a context of dialogue either, and consequently, I contend that the correctness of presumptions does not depend on the pragmatics of dialogical procedures. ${ }^{1}$

\footnotetext{
${ }^{1}$ In dealing with presumptions in terms of the conditions and consequences of making certain conversational moves, Walton's original aim was to provide a speech-act account of presumptions according to which presumptions would be "a distinctive kind of speech-act half way between assertion and (mere) assumption (supposition)" (Walton 1993, p. 125). On such approach, the correctness conditions of presumptions would be merely pragmatic, procedural: they would be a matter of the fulfilment of the dialogical conditions
} 
Importantly, that making a presumption does not involve making an inference does not mean that we cannot adduce presumptions as reasons for a conclusion, nor does it mean that we cannot adduce reasons to show a presumption to be correct. In fact, one of the main goals of this paper is to provide an account of the way in which presumptions enter into inferences as premises or conclusions, as well as an account of the conditions that determine whether these inferences are good or bad. Thus, even though I contend that making presumptions does not involve making inferences, I aim at both establishing the conditions for justifying presumptions, in the sense of determining which type of reason can be offered for showing a presumption to be correct, and determining what kind of claims a presumption can be a reason for. This said, the other main goal of this paper is to show that inferences including presumptions as premises or conclusions should be distinguished from other types of inferences for which the name "presumptive inferences" proves to be more adequate, namely, those determining the use of an epistemic modal such as "presumably".

\section{Preliminary considerations}

\subsection{Presumptions of law and presumptions of fact}

As pointed out before, within the field of law, presumptions play a paramount role, and their characterization, rationale and functions have been subject to intense analysis and debate for centuries.

for raising them. Later on, Walton (2008) has incorporated an inferential perspective in his account. Now he contends that "the notion of a presumption has to be defined at two levels: inferential and dialogical. At the inferential level, a presumption is defined as an inference to the acceptance of a proposition from two other propositions called a fact and a rule. At the dialogical level, a presumption is defined in terms of its use or function in a context of dialogue." (Walton 2008, p. 49). In this account, at the inferential level, the correctness conditions of presumptions would depend instead on the truth of the "propositions called a fact and a rule", which are the premises of the inference that gives rise to the presumption.

Walton does not seem to find any problem in this disparity of criteria for assessing presumptions. He is interested in both the correctness conditions for making presumptions and the correctness conditions for making presumptive inferences, which he takes to be one and the same thing. However, his distinction between a dialogical and an inferential 'level' has not been properly articulated, and this is why his account of presumptions results in ambiguity (see, e.g., Petrosky 2008, p. 392. As Petrosky observes, a similar ambiguity underlies Rescher's dialogical account as well). 
In Francis Wharton's definition, “the term prosumtio, in its classical sense, means exclusively a rule of law adopted for the purpose of determining the burden of proof" (Wharton, 1877: 16). Traditionally, however, the Law of Evidence has distinguished between presumptions of law and presumptions of fact. Wharton himself explained the difference between them in the following terms:

A presumption of law, in its true sense, is a presumption which, whether probable or improbable, is applied by statute, or by that which is equivalent to statute, to a fixed and constant condition of facts. A presumption of fact is a presumption applied by logic, aided either by common experience or by scientific research, to the exceptional and unique facts of each particular case. (Wharton, 1877: 27)

In David Kaiser's classical account, a presumption of law is "a rule of law which declares that one fact is presumed to exist if another fact or set of facts is proved" (Kaiser 1955, p. 253), whereas a presumption of fact is "the process of ascertaining one fact from the existence of another without the aid of any rule of law" (Kaiser 1955, p 254). As an illustration, Kaiser pointed out that "a presumption of guilt may arise from proof that the defendant, when arrested, was in possession of stolen goods and was attempting to leave the country. The presumption would be one of fact since there is no legal rule which compels the presumption to be made" (Ibid.)

In being mandatory rules, presumptions of law cannot be actually defeated. The most we can do is rebut them by showing that the conditions for making (or refraining from making) a certain assumption, such as the rule mandates, do not obtain. For example, by showing that the disappeared individual is alive, we are no longer obliged to assume that he is dead, and by showing that the defendant is guilty, we are no longer obliged to refraining from assuming that he is guilty. ${ }^{2}$

The distinction between presumptions of law and presumptions of fact is a well-established one within the field of law. ${ }^{3}$ However, philosophers and argumentation theorists have

\footnotetext{
${ }^{2}$ This is so in the case of non-conclusive presumptions of law, such as the presumption of innocence or the presumption of death. Contrastingly, conclusive presumptions of law such as the doli incapax rule unrestrictedly oblige us to assume, for example, that children under a certain age are legally irresponsible. In other words, the prescription to assume a certain claim that a conclusive presumption of law mandates does not have conditions of rebuttal. ${ }^{3}$ Actually, it is also customary to distinguish not only between conclusive and rebuttable presumptions, but also between presumptions with basic facts
} 
usually disregarded it. This fact may be due, at least in part, to Whately's influence, for he took the strategy of dealing with presumptions in general by considering legal presumptions as paradigmatic. ${ }^{4}$ For my part, in what follows I take for granted the difference between presumptions of law and presumptions of fact. Actually, I will put aside the analysis of presumptions of law-which, following up on Wharton and Kaiser's characterizations, I take to be rules of law prescribing or prohibiting certain assumptions ${ }^{5}$ - and I will focus on presumptions of fact instead. The latter are the kind of thing that may enter into ordinary argumentation as a premise or a conclusion - or as a warrant, as we are going to see. Thus, I will focus on ordinary statements such as "Dr. Livingstone, I presume," or "I presume his honesty," or "presumably, he is at home."

\subsection{Presumptions and burdens of proof}

One of the things all theorists agree on is the close relationship between the concepts of presumption and that of burden of proof. Certainly, placing the burden of proof is the immediate effect of any presumption of law. For example, famously, the presumption of innocence establishes that it is the prosecutor who has to prove guiltiness. But what about ordinary presumptions? Do they also place the burden of proof among discussants or legitimately shift it to an opponent?

First of all, it is important to notice that having the burden of proof is a procedural status, as it amounts to an answer to the

and presumptions without basic facts (see, for example, chap. 3 of McKeown 2014).

${ }^{4}$ Ullman-Margalit even refused the distinction between presumptions of fact and presumptions of law (Ullman-Margalit 1983: endnote 4) without actually feeling the need to argue for such refusal beyond a misguiding reference to Thayer's dismissal of the relevance of the distinction regarding the Law of Evidence (Thayer 1898: 339).

${ }^{5}$ One of the reasons for thinking of presumptions of law not as mere procedural mandates establishing the burden of proof among the attorney and the prosecutor, but as general rules mandating to make or refraining ourselves from making certain assumptions is that these rules also mandate outside the law court, and not necessarily in dialogical contexts. For example, as it is well-known in the case of the presumption of innocence, journalists are also requested not to assume that defendants are guilty until so proven, and they are requested to do so even in non-dialogical argumentations, such as op-ed columns, etc. Of course, journalists and people in general are free to think as they wish, but law has the faculty to prohibit or mandate certain assumptions because, as I explain in section 3, assumptions are not beliefs, but rather ways of conducting oneself. At any rate, what a presumption of law establishes usually goes beyond the dialogical procedures in the law court, although, of course, it has a main impact on them. But I do not aim to defend this view any further, for my focus is just on ordinary presumptions.

(C) Bermejo-Luque. Informal Logic, Vol. 36, No. 1 (2016), pp. 1-25. 
question of how to correctly develop a certain exchange of reasons: if you have the burden of proof, it is you who has to provide reasons for your claim instead of, for example, merely dismissing an opponent's refusal of it. Contrastingly, if there is a presumption favouring your view, then it is your opponent who has to provide reasons for her resistance to accepting it. Does this mean that presumptions amount to procedural statuses as well? In my view, it is necessary to distinguish between the procedural consequences of making a (correct) presumption or having a (correct) presumption favouring our view, and the very nature of presumptions. It is only the former that involves a privileged status within a context of dialogue. Let me explain this point.

\title{
2.3 Correct and incorrect presumptions
}

In principle, merely making a presumption cannot be enough for shifting the burden of proof. Otherwise, proponents could always gain advantage just by presuming the adequate premises, whether or not such presumptions are acceptable after all. This is, in my view, the moral of Freeman's (1996) criticism against Walton's former account of presumptions:

\begin{abstract}
Walton, by contrast, seems to make presumption almost a matter of niceness or cooperative attitude of the participants in a dialogue towards each other. Given the right choice, what is to prevent a proponent from saying "I presume that slavery is morally acceptable; correct me if I'm wrong." "I presume that the Holocaust never happened; correct me if I'm wrong." If the concept of presumption is broad enough to accommodate such examples, given a context of dialogue, one wonders what normative force the concept has. (Freeman 1996, p. 289).
\end{abstract}

As Freeman's example would show, it is only if the presumption is correct that the proponent in an argumentative exchange may shift the burden of proof to the opponent. In other words, it is not presumptions, but correct presumptions what may involve a privileged status within an argumentative exchange. Consequently, in contrast with the nature of the burden of proof, the nature of presumptions cannot be merely procedural.

To be true, Freeman seems to take the concept of presumption to be a normative one, that is: a real presumption would always be a correct presumption. This would be the reason why he contends that "a statement is acceptable just when there is a presumption in its favor" (Freeman 2005: 21). However, this view somehow distorts our ordinary way of talking of 
presumptions and of the activity of presuming. For, ordinarily, we take it that we can presume that $p$ even if we presume it incorrectly, just as we can assert or explain that $p$ even if we assert it or explain it incorrectly. ${ }^{6}$ Certainly, Freeman might respond that, in making the incorrect presumption that slavery is morally acceptable, the individual would not be actually presuming, but doing something like intending to presume.

For my part, I think it is more natural to get rid of such a normative conception of presumptions, which, in my view, is far too influenced by the legal perspective mentioned above. As we have seen, on this view, presumptions are closer to mandatory rules, which is the reason why they cannot be really defeated, but only rebutted. Such a normative conception of presumptions makes sense within Freeman's goal of grounding the task of determining premise acceptability. For, so understood, presumptions would be good starting points for inquiry under uncertainty, which is also Rescher's reason for his interest in presumptions. Yet, in my opinion, this perspective only postpones difficulties by turning the task of inquiring under uncertainty into the task of determining whether or not something is a real presumption after all.

On the other hand, what would we say a drunk Mr. Stanley is doing if, instead of saying "Dr. Livingstone, I presume" to Dr. Livingstone, he were saying that to someone else in a very unwarranted, and yet sincere, way? Notice that not only what this drunk Mr. Stanley presumes is false, but also his very presuming it seems to be incorrect-just as Freeman should say of presuming that slavery is morally right or that the Holocaust never happened. In my view, our drunk Mr. Stanley is making a presumption after all, albeit an incorrect one.

In sum, presumptions do not seem to be equal to procedural statuses, but (being acknowledged to having made) a correct presumption involves (being acknowledged to have) a privileged procedural status within a context of dialogue. This is why determining the dialogical consequences of making a presumption requires, first of all, an account of the correctness conditions for presumptions themselves.

\subsection{Determining the correctness of a presumption}

But, how should we understand the task of determining whether a presumption is correct or not? Paradigmatically, Whately took

\footnotetext{
${ }^{6}$ Notice that this point does not mean that we can presume at will, just as we cannot assert or explain at will: as Speech-act Theory has shown us, asserting or explaining (and, I contend, also presuming) have constitutive conditions of performance.
} 
this task to be that of extensionally determining which particular presumptions are in fact correct. As it is well known, his seminal work on presumptions largely dealt with the acceptability of some particular rules for making presumptions. ${ }^{7}$ Contrastingly, contemporary scholars have been concerned with providing the correctness conditions for presumptions in general, as they assume that, outside the dispositions of law, whether a certain presumption is correct or not will always depend on the particular features of the case at stake.

At any rate, the question of determining the correctness conditions of presumptions is a key concern for those interested in the evaluation of argumentation containing presumptions. For, just as the correctness of an assertion determines the goodness of a piece of argumentation consisting of this assertion among other claims, the correctness of a presumption determines the goodness of a piece of argumentation consisting of this presumption among other claims. Certainly, argumentation theorists cannot take as their own task that of saying, extensively, which assertions are correct and which are not: that would amount to provide $a$ theory of all. Rather, in order to provide a model for the evaluation of argumentation consisting of assertions, it is enough to determine the correctness conditions for assertions, leaving it to the evaluator the task of ascertaining, by means of these criteria, whether a particular assertion is correct or not. Likewise, regarding presumptions and the evaluation of argumentation containing presumptions, our task as argumentation theorists would be that of determining the correctness conditions of presumptions, rather than providing a list of possible sources of correct presumptions.

\subsection{Correctness conditions for presumptions}

Most authors agree that the correctness conditions for presumptions involve not only epistemic considerations, but also pragmatic ones. For example, Ullman-Margalit contended that in order to establish that a certain presumption that $p$ is in good order, we may adduce not only that it could be the case that $p$, but also that, in making that presumption, we satisfy the practical need to proceed. Moreover, according to Ullman-Margalit, we can even adduce the moral rectitude or instrumental adequa-

\footnotetext{
${ }^{7}$ Like those based on the idea that every individual is innocent until $\mathrm{s} / \mathrm{he}$ is proven guilty; that a person or corporation owns that of which s/he/it is in actual possession; that existing institutions are acceptable; that books are harmless; that the opinions of people who have authority, as well as received opinions, are right; and that changes are to be resisted. (Whately, [1846] 1963, pp. 112-124).
}

(C) Bermejo-Luque. Informal Logic, Vol. 36, No. 1 (2016), pp. 1-25. 
cy of assuming that $p$ (Ullman-Margalit 1983, p. 146 and $\mathrm{p}$. 157). On this account, not only epistemic, but also pragmatic considerations of all kinds (procedural, instrumental, moral), may be adduced in order to show that a given presumption is correct.

Importantly, the view that presumptions have, among others, a practical rationale implies that a presumption that $p$ may be correct even if $p$ is false. This is why we must distinguish between making an incorrect presumption and presuming something that is actually false. Actually, as we are going to see, a presumption may be correct even if we know that what is presumed is false.

\subsection{Ordinary presumptions as elements of argumentation}

Taking into account the above considerations, I am going to argue for the view that ordinary presumptions are a type of constative speech-acts. As we are going to see, as such constatives, presumptions may enter into argumentation just as any other type of constatives. For example, a presumption may be the conclusion of a piece of argumentation. In this case, we would have argumentation showing a presumption to be correct, like: "when she cannot come, she always phones me; therefore, I must wait, I presume". Also, presumptions may be what we adduce as reasons for our claims: for example, "she will show up as usual, I presume; so, I'd rather stay calm". But there are other possibilities for a presumption to be part of a piece of argumentation, as we are going to see. Particularly, when the warrant of an inference is a presumption, we have a presumptive inference sanctioning the use of an epistemic modal such as "presumably."

\section{A proposed definition of ordinary presumptions}

Let me then propose the following definition of non-legal, ordinary presumptions: if asserting that $p$ is behaving so as to count as meaning that $p$ is true, presuming that $p$ is behaving so as to count as meaning that it is reasonable to assume that $p$. In other words, a presumption that $p$ would be the speech-act of putting forward $p$ as a reasonable assumption. Presuming that $p$ is making the presumption that $p .^{8}$

\footnotetext{
${ }^{8}$ I surmise that presumptions of law are called "presumptions" despite not being speech-acts but mandates because their corresponding rationale is that of a presumption: for example, the presumption that states that it is reasona- 
So understood, presumptions are speech-acts that may also be performed in non-dialogical contexts. ${ }^{9}$ Such speech-acts have their corresponding mental counterparts (just as assertions, promises, etc.), which are the mental events of deeming it reasonable to assume that something is the case.

Presumptions and their mental counterparts are different from assertions and beliefs: whereas in believing/claiming that $p$, we take/contend $p$ to be true, in presuming that $p$, we take-itto-be/contend-that-it-is reasonable - in some particular senseto assume that $p$, whether or not $p$ is true after all, and whether or not we know that it is/is not.

In this account, presumptions are different not only from assertions - which are also speech-acts, but categorical instead of tentative-but they are also different from assumptionswhich are not speech-acts but mere takings as true. In making the speech-act of presuming that $p$ we contend that it is reasonable to behave as if $p$ were true. Thus, presumptions are also different from presuppositions - which are not speech-acts either, but necessary assumptions for a claim to be true. Yet, if a certain proposition is a presupposition of your speech-act, then we can say that, in making that speech-act for which the truth of $p$ is a necessary condition, we are also presuming that $p$, in the sense of contending that it is reasonable to behave as if $p$ were true.

Thus defined, presumptions have a words-to-world direction of fit, so that, following Bach and Harnish's typology $(1979$, p. 41$)$, they are a type of constative speech-act. As a constative, a presumption that $p$ will be semantically correct if and only if $p$ is a reasonable assumption indeed - that is, if it is reasonable to assume that $p$; much in the same way in which an assertion that $p$ is semantically correct if and only if $p$ is true.

\footnotetext{
ble to assume that individuals are innocent until proven guilty, or that married men are the biological fathers of children born during their marriage, etc. ${ }^{9}$ Notice that the verb "presume" passes the performative test: "I hereby presume that he'll be punctual" is in good order. Certainly, correcting presumptions is a little bit different from correcting assertions: whereas there is only one way of correcting an assertion-which is to negate what the assertion asserts, we can correct a presumption such as "the Holocaust never happened, I presume", both in the sense of showing that it is not reasonable to assume so (we defeat the presumption) and in the sense of showing that what we presume is false (we rebut the presumption). Yet, presumptions and assertions have in common the fact that, in order to refuse a presumption or an assertion (i.e., "no, you're not presuming" or "no, you're not asserting"), we do not point at the way the world actually is regarding the topic in question, but at the fact that this communicative move does not meet the pragmatic/intentional conditions that constitute it as a speech-act (for example, we can refuse a presumption by saying that the speaker is violating the sincerity condition: "you're not actually presuming so because you cannot really take that assumption to be reasonable").
} 
Consequently, justifying a presumption that $p$ will be giving reasons showing that it is actually reasonable to assume that $p$.

According to this view, mere presumptions do not reverse the burden of proof: in principle, "Dr. Livingstone, I presume" does not place any burden of proof; at most, it is Mr. Stanley who might be required to justify such a presumption-in our account, by showing the corresponding assumption to be reasonable. It is only if a presumption that $p$ is deemed to be correct that the opponent in a dialogue may be required to offer reasons to show that, despite being reasonable to assume that $p, p$ is false after all.

When we put forward a presumption that $p$ in an argumentative exchange, we contend that it is reasonable to assume that $p$. If presuming that $p$ is deemed to be correct, that is, if it is reasonable to assume that $p$, we legitimately shift the burden of proof to the opponent regarding the acceptability of $p$. Importantly, however, the correctness of this presumption will not settle that $p$, but only that it is reasonable to assume that $p$. In turn, the opponent can try to either rebut or defeat the presumption. That is, as a counter-move to a presumption that $p$, the opponent may argue against $p$-i.e., against the issue itself - and thus try to rebut the presumption; or, alternatively, she can argue against the very presumption that $p$-and thus try to defeat the contention that it is reasonable to assume that $p .{ }^{10}$

Among the possible reasons for deeming the assumption that $p$ unreasonable, there is, of course, that of accepting something that is actually false. Yet, that $p$ is false may be, depending on the context, insufficient ground for dismissing a presumption that $p$. This is so because the correctness conditions of presumptions are, in the last resort, pragmatic. After all, in our account, the question that we have to answer in order to determine whether a presumption that $p$ is correct is "is it reasonable to assume that $p$ ?" and "assuming" is a kind of doing-i.e., that of taking something to be true, so that its reasonableness conditions belong to the realm of practical reason. As a consequence, in general, the reasons rendering it reasonable to assume that $p$ will be reasons showing that assuming that $p$ is something pragmatically adequate to do - namely, because it is a good means for certain end. Thus, if, like in most contexts of deliberation, our pursued end is having correct beliefs or avoiding false ones,

\footnotetext{
${ }^{10}$ In this respect we may explain that to criticize someone for being presumptuous is to criticize, for example, that he takes it to be reasonable to assume that you will be happy to have him for dinner without having been invited. The criticism goes against the reasonableness of the presumption as being something impolite to assume, even though it might have been true. "It's true, but don't presume it" is a sound advice at times.
} 


\section{Bermejo-Luque}

then, if evidence shows that the corresponding proposition is false or likely false, pointing at this evidence will be a means to show that our presumption is incorrect: the assumption will be inadequate as a means to achieve correct beliefs or avoid false ones, and we will have epistemic reasons against that presumption. However, as we have seen, there may be non-epistemic reasons making it reasonable to assume something. For example, assuming something may be adequate as a means to avoid false positives (as when we presume the innocence of defendants), or as a means to promote certain attitudes in others (as when we presume the honesty of our kids or students - even against evidence!), or as a means to increase efficiency (as when we presume that everyone has read the document under discussion); or a matter of politeness (as when we presume that the person we invited to our home is trying to be kind to us); or even a principled matter (as when we presume the value of human life).

This said, there is of course a limit to what it may be reasonable to assume against evidence: after all, assuming that $p$ involves behaving as if $p$ was true, which is something that, depending on the circumstances, might be too difficult to do when counter-evidence is overwhelming.

Finally, our account makes room for the idea that a presumption that $p$ can be more or less weighty: it will depend on how reasonable the assumption that $p$ is, on how adequate it is to assume that $p$. For a jury member in a court trial, it is not merely reasonable, but compulsory to assume that the defendant is innocent until proven guilty. For an officer, it is reasonable, in general, to assume that soldiers will obey; yet, in particular cases, it might be more reasonable to assume that a soldier will not obey and make plans accordingly. At this juncture, one of these presumptions will trump the other because there are reasons showing it to be less reasonable or just wrong. ${ }^{11}$

\footnotetext{
${ }^{11}$ That a presumption may trump another presumption is a possibility that Whately and Rescher already envisaged. Actually, given their conceptions of presumption, this is the only way a presumption can be resisted. Contrastingly, in our account, a conflict of presumptions is a practical dilemma ("what is more reasonable to assume in this particular case") rather than an epistemic puzzle ("what is more likely to be true"). Such is the sense of "reasonable to assume" that we are adopting.
} 


\section{Putting forward a presumption that $p$ vs. concluding that presumably $p$}

The fact that a presumption may be correct even if we know that $p$ is false implies that a presumption that $p$ may be correct even if there is all evidence against $p$. In this sense, presumptions are not only different from beliefs and assertions in that the epistemic attitude that beliefs and assertions represent is categorical whereas presumptions are tentative, but also in that presumptions do not necessarily represent epistemic attitudes at all. To fully see this point, consider the following example used by Godden and Walton (2007, p. 323) as a criticism against Kauffeld's approach: a soldier has to raise the flag at dawn, even though he is very unreliable and tends to sleep in. According to Godden and Walton, we are entitled to presume of the soldier that he will raise the flag because it is his duty, but we are not justified in presuming that the soldier will raise the flag because we have all evidence that he won't.

Godden and Walton's example is part of their argument against Kauffeld's contention that presumptions are a matter of our entitlement to suppose something on the grounds that someone will try to make it the case on pain of social regret (Kauffeld 1995). According to Godden and Walton, Kauffeld's expectation-based model "confuses the social and the predictive components of presumption" (Godden and Walton, p. 323). As they point out, in an expectation-based model, our entitlement to presume that $p$ is grounded in another person's obligation to make $p$ true, but such obligation only gives some reason to believe that $p$ will be the case. If, as in the case of the soldier, we have better reasons to believe that not- $p$ will be the case instead, then, according to Godden and Walton, we are no longer justified in presuming that $p$. In their words: "being entitled is not always co-extensive with being justified or having some good reason" (Godden and Walton, p. 323).

However, Godden and Walton's argument presupposes that we can make sense of the distinction between being entitled to do something and being justified in doing it. But such distinction seems untenable, at least to this extent: in principle, being entitled to adopt a doxastic attitude or make a doxastic communicative move is the same as being justified in adopting it or making it. What Godden and Walton may say is that we are neither justified nor entitled in believing or asserting that the soldier will raise the flag. Yet, as pointed out before, believing or asserting is not the same as presuming.

Godden and Walton would reply that the problem is that we are confusing two conceptions of presumption: for it is one 


\section{Bermejo-Luque}

thing to presume something of someone, and it is another thing to presume that something is (or will be) the case. The idea would be that the criteria of correctness for the former kind of presumptions, i.e., presumptions grounded on expectations, is mainly social rather than epistemic, whereas the criteria for the latter kind of presumptions would be purely epistemic. According to Godden and Walton, "it is this epistemic sense of presumption that is most important to a theory of argument. After all, we want to know whether the presumption is justified." (2007, p. 323). In their view, presuming that the soldier will do his duty is unjustified, even though we are entitled to presuming of him that he will do his duty, because "the fact that a person is not likely to do something, does not change the fact that he ought to" (2007, p. 323).

However, this distinction does not seem to work; after all, presuming something of someone is also a form of 'presuming that': in presuming of the soldier that he will do his duty, we are also presuming that he will do his duty. At any rate, such distinction seems arbitrary: why a presumption based on reasons other than epistemic could not be justified? And why should we dismiss these presumptions as uninteresting for a theory of argument?

In my view, Godden and Walton's plea for an epistemic account of presumptions involves a different distinction, namely, that between taking a presumption that $p$ to be correct and contending that presumably $p$. For, in principle, a correct presumption that $p$ only settles that it is right to presume that $p$ or, alternatively, that it is wrong to presume that not- $p$. Yet, the correctness of a presumption that $p$ does not necessarily settle anything about the epistemic credentials of $p$. In contrast, by contending that presumably $p$, we do express the epistemic status of $p$. So, why is this so? What is presuming that $p$ as different from contending that presumably $p$ ?

To begin with, just by correctly presuming that $p$, we cannot take it that presumably $p$. This is why, for example, if the victim says to the judge "But he did it!" the judge can reply "I believe you; but I'll presume that he is innocent until proven guilty;" whereas there would be something peculiar if he replied, "I believe you; but, presumably, he is innocent until proven guilty". Or, following our example, this is why it is right to presume that the soldier will do his duty, but it is not right to say that, presumably, the soldier will do his duty. In other words: $p$ being the content of a correct presumption is not the same as $p$ being presumably the case. In our account, this is so because, in order to reject a presumption that $p$, we have to deny that it is reasonable to assume that $p$. 
Thus, following the insight of Ullmann-Margalit's and other legal accounts, our conception of presumptions allows for the possibility of justifying presumptions on grounds other than epistemic ones. Just as the rationale for the presumption of innocence is not justified on the epistemic ground that defendants are likely to be innocent, but on the pragmatic ground that, assuming their innocence is, in general, a good means to avoid false positives, at times, what makes it reasonable to assume that a soldier will do his duty is not that it is likely that he will do it, but, for example, that assuming otherwise would put military authority into question. Contrastingly, in order to reject that presumably $p$, we can adduce, for example, that, in fact, $p$ is false. As already pointed out, the falsity of $p$ may be insufficient ground for rejecting a presumption that $p$; yet, it is always a means to reject the claim that presumably $p$.

Finally, something like "It may or may not come, I presume" may be fine in some circumstances; yet, there is something peculiar in "Presumably, it may or may not come". In the following section I explain these phenomena by pointing out that claims of the form "presumably $p$ " are the conclusion of presumptive arguments. Or more exactly: that in putting forward that presumably $p$, we are making a second order speech-act of concluding by drawing a presumptive inference. So, what is a speech-act of concluding and what is a presumptive inference? And what makes each of them correct?

\section{A linguistic normative model of argumentation}

In Bermejo-Luque (2011) I proposed a linguistic normative model for argumentation, LNMA, that follows Bach and Harnish's (1979) Speech Act Schema in order to characterize acts of arguing as second order speech-act complexes. Particularly, I characterized acts of arguing as speech-acts composed of a speech-act of adducing (i.e., a reason) and a speech-act of concluding (i.e., a target-claim). On this account, acts of adducing and acts of concluding are constatives - whether directly or indirectly performed, literal or non-literal; but they are second order because they can only be performed by means of first order speech-acts. According to this model, a performance of, for example, "I promise I'll take care, don't worry"-which, in principle, just involves two first order speech-acts, i.e., a promise and a request - turns into a speech-act complex of arguing because they turn into the constative speech-act of adducing that the arguer commits herself to take care and the constative speech-act of concluding that the addressee should not worry. 


\section{Bermejo-Luque}

Two speech-acts become an act of adducing $\mathrm{R}$ and an act of concluding $\mathrm{T}$ because of their relationship to an implicit inference-claim whose propositional content is "if $R$, then $T$." In a few words, it is by attributing to the speaker the implicit inference-claim "if (it is true that) I commit myself to take care, then (it is true that) you should not worry" that we interpret her utterances of "I promise I'll take care" and "Don't worry", as a single speech-act - namely, an act of arguing. Normally, the fact that the speaker has used some epistemic modal (like "probably," "necessarily," "presumably," etc.) or an illative expression like "so," "therefore," "since," "consequently," etc. is what authorizes us to interpret the speaker's performance as a speechact of arguing. Very roughly, the idea is that, illocutionarily, acts of arguing, so characterized, count as attempts at showing a target-claim to be correct. To the extent that they succeed in thiswhich means that the target-claim has been correctly qualified by a certain epistemic modal (semantic conditions) and that the act of arguing is a good means for showing this (pragmatic conditions) - they will be deemed good argumentation.

In principle, we can make explicit the variety of ways in which we can put forward a certain semantic content $p$ in constative speech-acts by saying things like " $p$ is true," " $p$ is (more or less) probable," " $p$ is (more or less) acceptable," " $p$ is (more or less) plausible," " $p$ is necessary," " $p$ is possible," or even " $p$ is a (more or less) reasonable assumption". In the latter case, our constative is a presumption, as argued before. Let us name ontological modals the modals by means of which we can make explicit the type and degree of pragmatic force of any of the constatives constituting the act of arguing (including the inferenceclaim): after all, constatives are speech-acts meant to communicate how the world is. In making explicit the pragmatic force of such constatives, we make plain assertions in turn-such as the plain assertion that $p$ is true, or that it is (more or less) probable, or possible, or plausible, or necessary, or a (more or less) reasonable assumption, etc. When we put forward a propositional content with the pragmatic force that such propositional content actually deserves as a representation of the world, we make first order constatives that are semantically correct. For example, a presumption that $p$ is correct if and only if $p$ is a reasonable assumption-which is, in our account, what we mean when we presume that $p .^{12}$

\footnotetext{
${ }^{12}$ In acknowledging different types of ontological modals I am endorsing the view that constatives can have values other than true or false. And assuming probability values is not the only way to endorse this view. For example, we can also acknowledge ontological plausibility values: a claim like "Mike is bald" may be a better or worse representation of Mike's amount of hair at the
} 
Contrastingly, the modal that expresses the pragmatic force with which we draw our conclusion in the act of arguing is an epistemic modal. This modal is meant to communicate our credentials for concluding, i.e., the type and degree of support that our reasons are supposed to confer on our target-claims because of our inference-claims. In saying that a claim holds truly, necessarily, possibly, plausibly, probably, presumably, etc. (i.e., that likely $p$, that it might be the case that $p$, that certainly $p$, that presumably $p$, etc.), we are saying something about the status of this claim as knowledge, about the confidence that we may put on it, or our epistemic entitlement to it. In this account, epistemic modals are meant to communicate how good our reasons for our claims are. And, as we are going to see, they are a function of the ontological modals that correspond to the implicit inference-claim and to the constative constituting the content of the speech-act of adducing. Thus, in any conclusion-i.e., the second order speech-act of concluding-we can find, either explicitly or implicitly, not only its ontological modal as a first order constative, but also the epistemic modal that indicates the force with which this claim is concluded in the whole speech-act of arguing in virtue of the ontological modal attributed by the speaker to its warrant.

LNMA adopts Toulmin's conception of material inference by taking the elements of any act of arguing to be a pragmatic linguistic reconstruction of the elements of Toulmin's model of argument. In this model, arguments are those representations of acts of arguing that layout their inferential relations. Thus, in LNMA the constitutive elements of arguments are: premise $(P$, corresponding to the speech-act of adducing, i.e., the reason in the act of arguing), conclusion ( $C$, corresponding to the speechact of concluding, i.e., the target-claim in the act of arguing), warrant ( $W$, corresponding to the inference-claim in the act of arguing) and the epistemic and ontological modals of each speech-act (em, om, corresponding to the pragmatic force with which each constative of the act of arguing has been put forward, either implicitly or explicitly). Hence, an ascription of modals (eventually, the ascription made by the arguer) is part of the layout of arguments, and the semantic evaluation of an act of arguing is the process of determining the right ascription of modals to each represented claim (that is, whether or not the

present time, and in case we cannot take it to be plainly and simply true/false, we can take it to be just plausible to some degree in this ontological sense. Similarly, making a presumption, that is, putting forward a proposition as a reasonable assumption, is a way of saying something about this proposition's value as a representation of the world. 


\section{Bermejo-Luque}

ascription made by the arguer is correct after all). This model of argument can thus be outlined as follows:

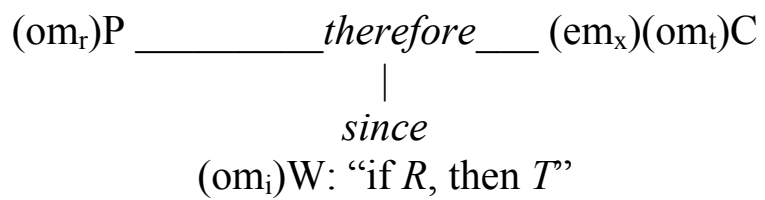

(Remarkably, the content of the antecedent, $R$, and the consequent, $T$, is the content of the corresponding first order constatives joint with their corresponding pragmatic forces).

Let $\varphi$ represent the function that assigns, for each ontological modal of a conditional, the epistemic modal that must be used in drawing a conclusion having this conditional as its warrant-or, in other words, the term that must be used for expressing the pragmatic force of any speech-act of concluding having a conditional so qualified as its inference-claim.

$$
\varphi\left(\mathrm{om}_{\mathrm{i}}\right)=\mathrm{em}_{\mathrm{i}}
$$

In this account, an argument is valid if and only if $\mathrm{em}_{\mathrm{i}}=\mathrm{em}_{\mathrm{x}}$ and $\mathrm{om}_{\mathrm{i}}$ is correct-in the sense that it is the ontological modal that actually corresponds to the inference-claim as a constative. That is, the argument will be valid if and only if the epistemic modal that the speaker has used for concluding is the epistemic modal that $\varphi$ assigns to the ontological modal of her implicit inference-claim and this ontological modal is the one that this inference-claim actually deserves. Let me offer a few examples to make all this clearer.

According to LNMA, deductive arguments are arguments whose warrants are meant to be necessary truths, so that, in case of being valid, they entitle us to epistemically qualify our conclusions with a "necessarily". Thus, arguments such as "She is in the garden or in the living-room, and she is not in the garden; so, necessarily she is in the living-room" or "This may be red; so, necessarily, it may be coloured" are deductive and valid because their corresponding warrants are the necessary truths: "if (it is true that) she is in the garden or in the living-room, and (it is true that) she is not in the garden, then (it is true that) she is in the living-room" and "If (it is possible that) this is red, then (it is possible that) it is coloured". Likewise, valid probabilistic arguments are arguments whose warrants are (more or less) probable, so that they entitle us to epistemically qualify our conclusions with a "(more or less) probably/likely". For example, "Our 
currency is loosing value; so, very probably, the inflation rate will raise" has as its warrant "if (it is true that) our currency is loosing value, then (it is true that) the inflation rate will raise", which is very probable indeed (making the argument inductively valid in turn).

In turn, plausible arguments like "Your business is not working as expected; plausibly, it needs renovation" or "It holds up through $4 \times 10^{18}$ that every even integer greater than 2 can be expressed as the sum of two primes; so, plausibly, that every even integer greater than 2 can be expressed as the sum of two primes is a mathematical (necessary) truth", would be arguments whose warrants are plausible truths, such as "if (it is true that) your business is not working as expected, then (it is true that) it needs renovation" and "if (it is true that) it holds up through $4 \times 10^{18}$ that every even integer greater than 2 can be expressed as the sum of two primes, then (it is necessary that) every even integer greater than 2 can be expressed as the sum of two primes."

Finally, a presumptive argument like "John's car is on the street; so, presumably, he is at home" is an argument whose warrant is the presumption "if (it is true that) John's car is on the street, then (it is true that) he is at home". All these arguments will be valid if their corresponding warrants are correct. Particularly, in the case of a presumptive argument like the one about John, it will be valid if "if (it is true that) John's car is on the street, then (it is true that) he is at home" is a correct presumption indeed; that is, if it is reasonable to assume so. ${ }^{14}$

\section{Assessing presumptive inferences}

In this account, inferring that presumably $p$ is inferring that $p$ on the basis of a warrant that is a presumption. In other words, saying that presumably $p$ is putting forward that $p$ "by reasonable assumption", and this is not just concluding on the basis of an

\footnotetext{
${ }^{13}$ In this model, validity is not co-extensive with deductiveness: "deductive," "probabilistic," "plausible" or "presumptive" are names for inferences, in the sense of "forms of inferring." But any of them may go wrong; that is, they may happen to be invalid. On the other hand, this model does not make a sharp contrast between deductive and inductive inferences, in the sense of inferences whose conclusions (are meant to) follow conclusively and those whose conclusions (are meant to) follow less than conclusively. For example, arguments whose warrants are just true entitle us to conclude with a "truly," and such qualification does not seem to fit well into any of these groups.

${ }^{14}$ Remarkably, presenting a conditional as a reasonable assumption is not the same as presenting its consequent as a reasonable assumption provided that the antecedent is true.
} 
assumption, but on the basis of an assumption that is taken to be reasonable. Such arguments will be valid if the presumptions that constitute their warrants are correct presumptions indeed. And they will be semantically good arguments if their reasons and warrants are both correct.

Now we are in a position to explain certain phenomena related to the distinction between presuming that $p$ and maintaining that presumably $p$. The reason why "It may or may not come, I presume" sounds acceptable is that, in a given occasion, it may be sensible to remind ourselves that it is reasonable to assume this fact. Yet, it seems peculiar to maintain that "presumably, it may or may not come," because this is to make a speech-act of concluding based on an inference-claim whose consequent is a tautology. Such an inference-claim is a conditional that is more than a mere presumption: it is a (logically) necessary truth, and because of that, the epistemic modal that the speaker is expected to use in this case is something like "necessarily", not a mere "presumably".

Presumptive inferences are characteristically defeasible. In our account, this is so because the warrant of a presumptive inference is a conditional put forward as a reasonable assumption, and the reasonableness of an assumption depends on the circumstances. Actually, an arguer may secure her contention that $p$ is a reasonable assumption under the condition that other circumstances do not obtain. For example, "if John's car is on the street, then he is at home", may be secured as a reasonable assumption under the condition that he is not at Sam's. ${ }^{15}$

When we presume "if $p$ then $q$ ", what we do is to present "if $p$ then $q$ " as a reasonable assumption. In turn, when we conclude that presumably $q$ from the fact that $p$, we do so on the basis of $p$, not on the basis of that conditional, which is just the way in which we make explicit the inferential step from reason to conclusion. Eventually, our concluding will take into account that the presumption has not been defeated. Particularly, we may consider that, as far as we know, there isn't evidence against the proposition "if $p$ then $q$ ", so that assuming it would no longer be reasonable - at least, from an epistemic point of view. ${ }^{16}$ This is why there seems to be a close relationship between presumptive

\footnotetext{
${ }^{15}$ Following Toulmin's model, that would be a rebuttal for the warrant.

${ }^{16}$ When we use presumptions as warrants for our inferences, we mostly do it for epistemic purposes. This is why the normal uses of "presumably" have an epistemic rationale. However, inferences like "This strategy has many negative impacts on the population; presumably, it will be their last option" may be based on presumptions that are not reasonable assumptions for epistemic reasons, but, for example, for moral ones.
} 
inferences and arguments from ignorance, as Walton (1993; 2008) has observed.

Actually, Walton contends that presumptive inferences are a type of argument from ignorance, and he says that we must not be reluctant to admit this view by uncritically assuming that every instance of an argument appealing to ignorance is a fallacy: in his view, just as other forms of arguments from ignorance, presumptive inferences are arguments from ignorance that are not necessarily fallacious.

Yet, even though I agree with Walton that not every instance of an argument appealing to ignorance is a fallacy, I think, contrary to him, that there is an important difference between a presumptive inference and a typical argument from ignorance. This difference would be the reason why typical arguments from ignorance tend to be fallacious whereas presumptive inferences do not involve such a tendency. The difference is that presumptive inferences appeal to ignorance in order to point out that a possible defeater for the warrant (which is a presumption) does not obtain, whereas typical arguments from ignorance characteristically appeal to ignorance as the very reason to conclude. In other words, the reason to accept the conclusion of a presumptive inference is not that, so far, we don't know that it is false; rather, the appeal to our ignorance is just a way of defending the correctness of our warrant against a possible defeater: "as far as we know, John is not at Sam's; therefore, if John's car is on the street, he is at home, I presume".

On the other hand, when the inference-claim of a speechact of arguing is a presumption, the arguer sets herself free from the task of providing reasons to show this conditional to be true. She just states that it is reasonable to assume such conditional. But this does not mean that she has set herself free of any dialectical obligations whatsoever. In particular, she may be required to show the conditional to be a reasonable assumption indeed.

Finally, in our account, Freeman and Rescher's contention that presumptions are unavoidable points of departure in argumentation because they are the basis of premise acceptability would be misleading. Certainly, when we assess the reasons of a piece of argumentation for which no further reasons have been offered, we may be benevolent and presume that they are true. Moreover, in following arguments in Robert Pinto's sense of "following an invitation to inference" (Pinto 2001, Ch 7), we frequently concede what the speaker says because we presume not only veracity, but also knowledge of what he says. However, the typical reasons that arguers offer are seldom presumptions. Most of the times, they are plain assertions, whose conditions of correctness are very different from those of presumptions. Thus, 


\section{Bermejo-Luque}

for example, if the arguer makes a plain assertion that $p$ - that is, if she contends that $p$ is true-and $p$ is false, it doesn't matter whether or not it is reasonable to assume that $p$ : her argument will be semantically flawed anyway.

\section{Conclusions}

In our proposed account, presumptions are speech-acts that do not necessarily require a context of dialogue for taking place. In this regard, they are like assertions and other constative illocutions such as predictions, factual hypotheses, etc. As such, they may enter in argumentation as reasons, conclusions or inferenceclaims, just as any other constative. We deem a presumption that $p$ to be correct if and only if it is reasonable to assume that $p$. Accordingly, a presumption that $p$ will be justified if and only if it can be shown that it is reasonable to assume that $p$. In turn, we take presumptive inferences to be inferences sanctioning the use of an epistemic modal such as "presumably". A presumptive inference will be valid if and only if its warrant is a correct presumption indeed. ${ }^{17}$

In "A Theory of Presumption for Everyday Argumentation," Godden and Walton (2007) proposed the following questions as key issues within the study of presumptions as argumentative devices:

1) What gives rise to presumptions? What types of considerations should contribute to an explanation of their normative foundations?

2) Should presumptions arise from the making of a prima facie case, or by proposing a defeasible argument, or are other practical considerations also required?

3) What standard of rebuttal is appropriate to presumptions employed in argument? Can they only be rebutted by counter-presumptions? Does a rebuttal really require a proof of the negation of the presumption?

According to the proposal offered here, these questions would have the following answers: Because a presumption is a type of constative speech-act, it rises as a communicative move for establishing the representative value of a propositional content. In particular, the correctness conditions of presumptions depend on whether or not it is reasonable to assume something in given circumstances.

\footnotetext{
${ }^{17}$ This is just an outline, because, as argued before, presumptions can be more or less weighty.
} 
Importantly, the proposition that we presume is not the whole presumption, but what is presumed in the speech-act, just as the proposition that we assert is not the whole assertion, but what is asserted in the speech-act. The presumption that $p$ is the speech-act of presuming, which acquires a certain epistemic status if such a presumption is deemed to be correct. In this respect, presumptions behave as any other constative: putting forward a proposition as true is asserting it, and deeming this assertion to be correct is a move that has argumentative and nonargumentative implications. Likewise, putting forward a proposition as reasonable to assume is presuming it, and deeming this presumption to be correct also has argumentative and nonargumentative implications.

In order to get our presumptions to be regarded as correct we can justify them, in the sense of showing them to be correct. In our account, justifying a particular presumption that $p$ involves offering reasons showing that, in the circumstances, it is reasonable to assume that $p$. To this end, not only epistemic but also practical considerations of all kinds can be adduced. As we have seen, arguments for justifying presumptions are normally defeasible arguments, for what it may be reasonable to assume at a certain moment may turn to be unreasonable later on. Yet, we should not confuse this type of defeasible arguments with the sort of defeasible arguments presumptive arguments are.

Importantly, the fact that we can justify our presumptions does not mean that presumptions can only be put forward if we have reasons for them. Also in this respect, presumptions enter into discourse just like any other constative: for example, we introduce assertions in our discourse without always giving reasons for them.

In order to defeat a presumption that $p$, both epistemic and practical reasons can be adduced. These will not be reasons for showing that not- $p$, but reasons for showing that it is not reasonable to assume that $p$. In turn, in order to defeat a conclusion that presumably $p$, we can reject the reason for it, we can reject the presumption being the warrant of this argument, or we can just try to show that, on the contrary, not- $p$.

Finally, as Freeman, Rescher and Walton pointed out, presumptions are invaluable tools for reaching conclusions under uncertainty. In our account, this role of presumptions has to do with the fact that the speech-act of presuming enables us to treat what is presumed-i.e., the propositional content of the presumptions - as true, which, at times, is the only means to go on. Such permission does not require us to know that what is presumed is true, but only to know that it is reasonable to assume it - that is, to treat it as if it were true. The fact that, in some 


\section{Bermejo-Luque}

cases, it is easier to show that it is reasonable to assume something than to show that it is true explains why, in situations of ignorance, it is wise to adopt presumptions as starting points. Such starting points may, nevertheless, be justified, rebutted or defeated in turn.

Acknowledgements: I wish to thank Prof. Javier Rodríguez Alcázar and Prof. Raymundo Morado for their helpful comments and criticisms. The work presented in this paper has been financed by a Ramón y Cajal Research Fellowship and by the research project FFI2014-54681-P of the Spanish Ministry of Science and Innovation.

\section{References}

Bermejo-Luque, L. 2011. Giving reasons. A linguistic-pragmatic approach to argumentation theory. Dordrecht: Springer.

Bach, K. \& R. Harnish. 1979. Linguistic communication and speech acts, Cambridge, MA: MIT Press.

Freeman, J. B. 1996. Review of Plausible argument in everyday conversation, by D. Walton. Informal Logic, 18(2\&3): 288-298.

Freeman, J. B. 2005. Acceptable premises: An epistemic approach to an informal logicp problem. Cambridge: Cambridge University Press.

Hansen, H. V. 2003. Theories of presumptions and burdens of proof. In Informal Logic at 25: Proceedings of the Windsor Conference, eds. J.A. Blair et al. Windsor, ON: Ontario Society for the Study of Argumentation (OSSA).

Godden, D. \& D. Walton. 2007. A theory of presumption for everyday argumentation. Pragmatics \& Cognition, XV(2): 313-346.

Kaiser, D. 1955. Presumptions of law and of fact. Marquette Law Review XXXVIII(4): 253-262.

Katzner, L. 1973. "Presumptions of reason and presumptions of justice. The Journal of Philosophy, LXX(4): 89-100.

Kauffeld, F. J. 1995. On the difference between assumptions and presumptions. In Argumentation and Values: Proceedings of the Ninth SCA/AFA Conference on Argumentation, ed. S. Jackson, 509-514. Annandale, VA: Speech Communication Association.

McKeown, P. (Ed.). 2014. Evidence, $17^{\text {th }}$ ed. The City Law School. Oxford: Oxford University Press.

Morgan, E. 1937. Presumptions. Washington State Law Review and State Bar Journal XII(4): 255-281.

Petrosky, K. 2008. The public face of presumptions." Episteme V(3), 388401.

Pinto, R. C. 2001. Argument, inference and dialectic: Collected papers in informal logic. Dordrecht: Springer.

Rescher, N. 1977. Dialectics: A controversy-oriented approach to the theory of knowledge. Albany, NY: State University of New York Press.

Rescher, N. 2006. Presumption and the practices of tentative cognition. Cambridge: Cambridge University Press.

Sidgwick, A. 1884. Fallacies: A view of logic from the practical side. New York: D. Appleton and Company. 


\section{Being a Correct Presumption 25}

Thayer, J. 1898. A preliminary treatise on evidence at common law. Boston: Little, Brown and Company.

(Accessible at https://archive.org/details/cu31924017931712)

Ullman-Margalit, E. 1983. On Presumptions. The Journal of Philosophy, $\operatorname{LXXX(3):~143-163.~}$

Walton, D. 1992. Plausible argument in everyday conversation. Albany: State University of New York Press.

Walton, D. 1993. The speech-act of presumption. Pragmatics \& Cognition, I: $125-148$.

Walton, D. 1996. Argumentation schemes for presumptive reasoning. Mahwah, NJ: Lawrence Erlbaum.

Walton, D. 2008. Presumption, burden of proof and lack of evidence. L'Analisi Linguistica e Letteraria, XVI: 49-71.

Wharton, F. 1877. Disputed questions of evidence: Relevancy, presumptions of law and presumptions of fact. St. Louis: G.I. Jones and Company.

Whately, R. [1846] 1963. Elements of rhetoric. $7^{\text {th }}$ ed. D. Ehninger, ed. Carbondale. IL: Southern Illinois University Press. 